\title{
Analysis of Affected Surface Zone Created by Different Cutting Technologies
}

Ludmila Kučerová, Antonín Račický, Iveta Tỉchá

Regional Technology Institute, Faculty of Mechanical Engineering, University of West Bohemia in Pilsen, Univerzitni 8, 30614 Pilsen, Czech Republic.E-mail: skal@rti.zcu.cz, racickya@rti.zcu.cz, ichenati@rti.zcu.cz

Three cutting technologies, plasma, laser, and acetylene, were used to produce the same geometry of a hole with $33 \mathrm{~cm}$ diameter. The plates of the same steel St-37 (1.0038, ČSN 11375) with a thickness of 50 $\mathrm{mm}$ were used in all three cases and the aim of the work was to evaluate and compare microstructure changes of the cut surfaces. Longitudinal and transverse samples were taken from all cuts for subsequent analysis. Light and scanning electron microscopy of surface and below-surface areas were carried out at all samples. Hardness profiles were determined by micro-hardness and nano-hardness measurements. Based on these results, the depth of material that was influenced by cutting was established by image analysis of light micrographs, micro-hardness measurement and nano-hardness measurement. It was found out, that all three technologies influence significantly microstructure and surface hardness of cut steel. Acetylene cutting resulted in the deepest affected zone consisting of several layers with gradually changing microstructures based on various ferritic-carbidic morphologies.

Keywords: laser, plasma, acetylene, surface modification

\section{Introduction}

Laser, plasma, or oxygen-acetylene cutting methods are widely used for cutting of steels and most of the research works concerning these methods have paid attention to the effect of cutting parameters on the roughness of the cut surface. Surface roughness has been a single parameter used to assess the quality of cut surfaces, as the manufacturers are mostly interested in the control of the most visible parameters of the cut surface, which are roughness and edges. Moreover, these parameters could be determined relatively easily and quickly [1-6]. However, the thermal cutting methods do not affect only the roughness of the cut surfaces, the heat generated in the cut area can also influence the microstructure and mechanical properties of the surface layer of cut material [7-10]. This work describes the difference in affected layers of steel that was cut by these three methods.

Laser cutting is often used to process metals, due to its low and localized heat input into the material and production of high surface quality without mechanical deformation. In comparison with other thermal methods, it should, therefore, result in the thinnest layer of re-melted material and heat-affected zone. [1] This method enables the cutting of various geometries. Increasing thicknesses of cut material results in increased surface roughness, which could have a negative impact on fatigue life. However, the fatigue life of laser cut parts is still generally better than the fatigue life of plasma or oxygen-acetylene [2-6]. Plasma cutting melts material at extremely high temperatures around $10000{ }^{\circ} \mathrm{C}$, which originate from dissociation of gas molecules passing through an electric arc. The molten material is blown away from the cut by the assisting gas [8-12]. The good quality of the cut can be achieved by a suitable choice of cutting parameters. The biggest advantages of oxygen-acetylene cutting are the simplicity and mobility of used equipment and low acquisition and running costs. The disadvantage of the acetylene cutting method is the substantial heating of cut material, which creates large heat-affected zone and residual stresses [13-15].

\section{Experimental program}

Large holes with $330 \mathrm{~mm}$ diameter were cut from $15 \mathrm{~mm}$ thick plates of St-37 steel (1.0038, ČSN 11375) in the annealed state (Fig. 1). The material, cut shape, and thickness of the plate were chosen according to commercial requirements and three relatively common cutting technologies were used to produce the same size of the hole: laser, oxygen-acetylene, and plasma. The cutting parameters of each technology were chosen based on commercial practice. Laser cutting machine Trulaser 30301 was used applying the cutting speed of $1.17 \mathrm{~mm} / \mathrm{min}$. Four-torch oxygenacetylene cutter VANAD F cut the steel at 0.33 $\mathrm{mm} / \mathrm{min}$ and plasma cutter HYPERTHERM used cutting speed of $1.5 \mathrm{~mm} / \mathrm{min}$. Four metallographic samples were prepared from each cut surface, two in a longitudinal and two in a transverse direction. Transverse cross-sections were prepared to evaluate the changes in the depth of the influenced layer across the thickness of the plate. For this purpose, light microscope Olympus BX61 with the motorization of 
all three axes was used to provide a good resolution stitched up an image of the whole cross-section.

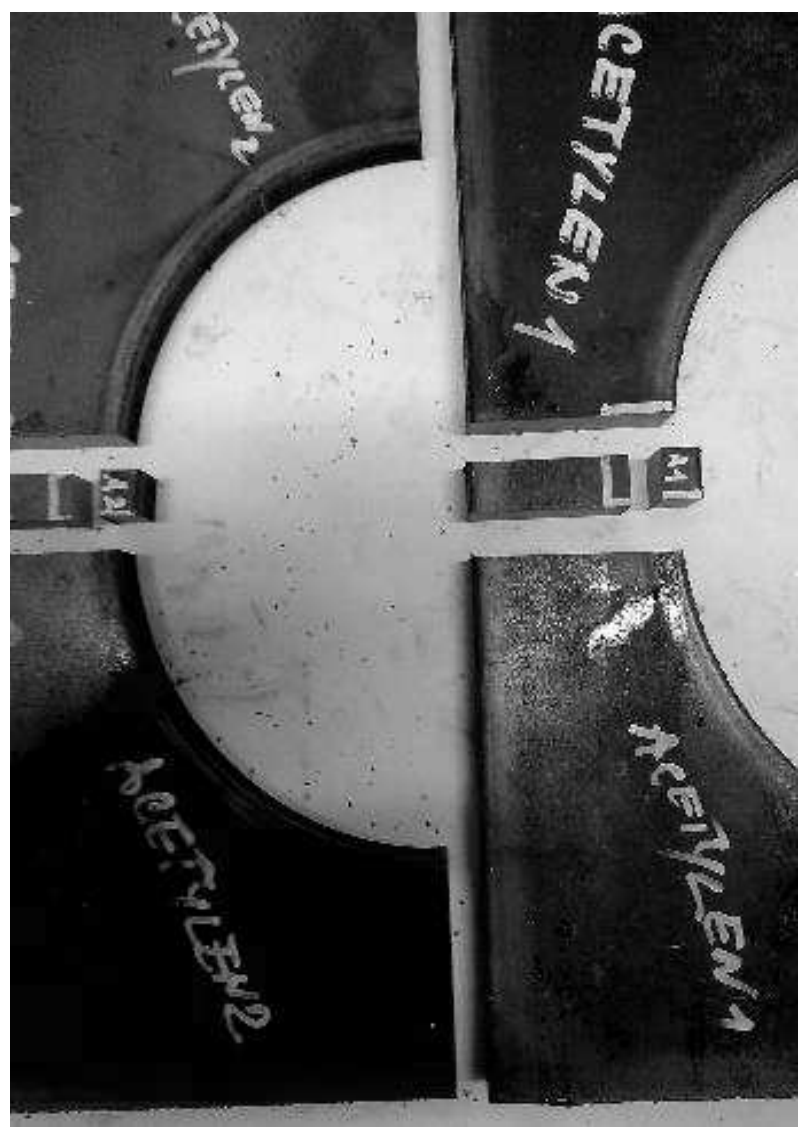

Fig. 1 Plate with a circular hole cut by oxygen-acetylene method and samples for analysis $(A 1, A 2)$

The side of the plate with a thicker influenced layer (i.e. the bottom side) was used for the preparation of longitudinal metallographic cross-sections. Longitudinal cross-sections were used to measure the depth of the influenced layer by image analysis of light micrographs and in a change of micro and nano-hardness over the depth below the surface. Therefore, microhardness HV0.1 was measured using UHL VMH-002V with an imprint spacing of $0.05 \mathrm{~mm}$. Nanohardness development was evaluated by NanoTest
Vantage (MicroMaterials), using a loading force of 0.1 $\mathrm{g}(0.98 \mathrm{~N})$ with the distance between imprints being 46 micrometres. Image analysis was carried out at three randomly taken light micrographs, average values of 15 measurements are given in the Results. For samples cut by acetylene, the analysis had to be performed at stitch images, as it was too thick to fit in a single light micrograph taken with the lowest magnification objective $5 \mathrm{x}$.

\section{Results and discussion}

\subsection{Metallography of cut surfaces}

Longitudinal and transverse cross-sections were prepared by standard metallographic methods of grinding, fine grinding, polishing, and final etching by $3 \%$ Nital. Metallographic cross sections were documented with light and scanning electron microscopy. The used St-37 steel plate was in an annealed state, possessing a ferritic-pearlitic microstructure (Fig. 2). The surface cut by acetylene had the microstructure consisting of acicular ferrite, proeutectoid ferrite, and coarse bainitic blocks with coarse laths of lower bainite (Fig. 3 a). The influenced microstructure was so deep, it was not possible to evaluate the depth optically from one micrograph taken by the lens with a magnification of $5 \mathrm{x}$ and had to be determined from stitched images (Fig. 4). The influenced layer consisted of several areas with a gradually changing microstructure. The area with increased ferrite fraction was placed just below the surface. Ferritic grains coarsened at first and the microstructure was refined again deeper below the surface, gradually transferring into the base ferriticpearlitic microstructure of the plate with rather a regular distribution of pearlitic blocks.

The laser-cut surface had a distinctive quenched microstructure containing the mixture of martensitic areas with occasion bainitic laths at the surface (Fig. $3 \mathrm{~b})$. Quenched microstructure with predominantly bainitic microstructure and the occasional occurrence of martensite was found in the surface of samples cut by plasma (Fig. 3c).
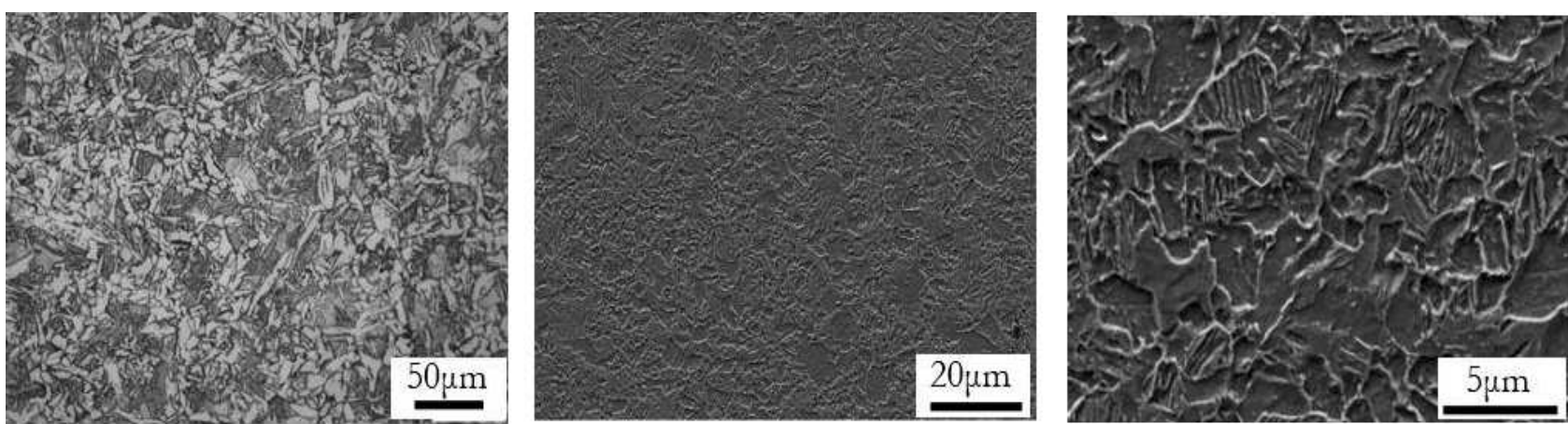

Fig. 2 Ferritic-pearlitic microstructure of the base material of the steel, viewed with increasing magnification. 


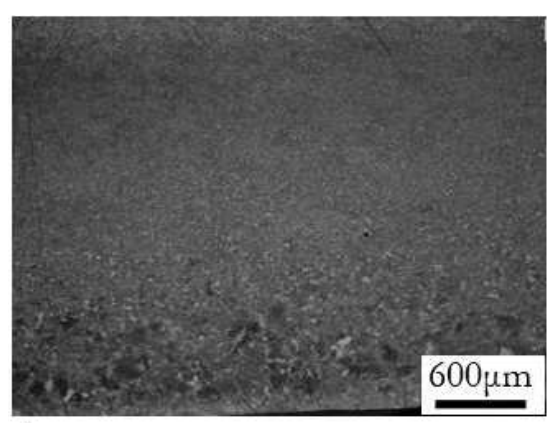

a)

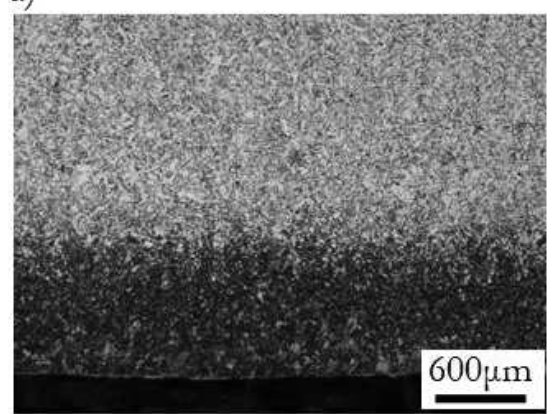

d)

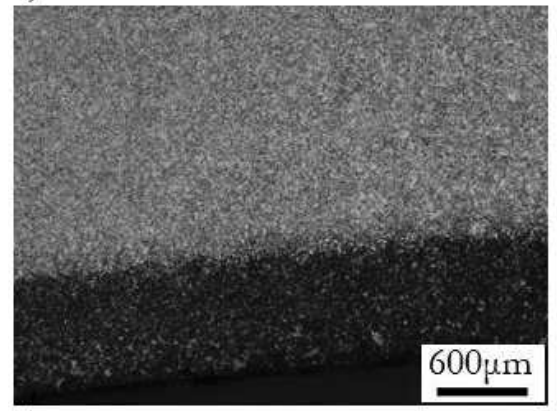

g)

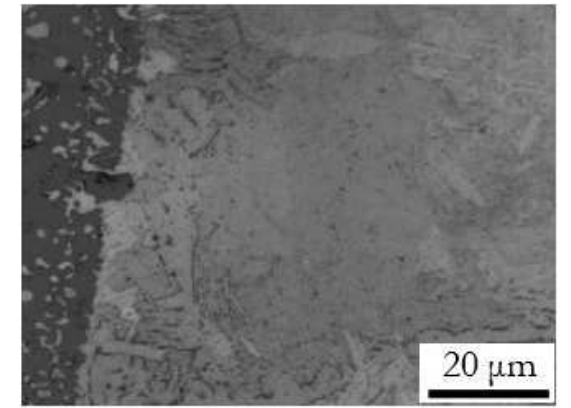

b)

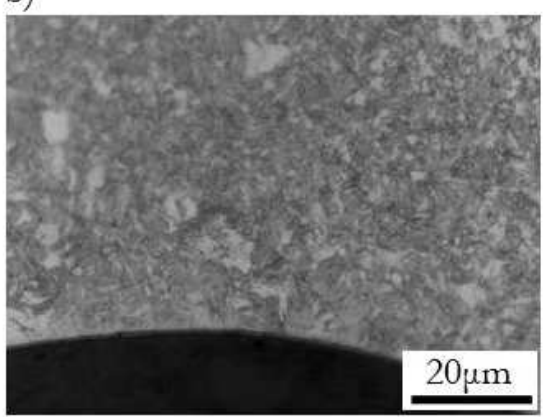

e)

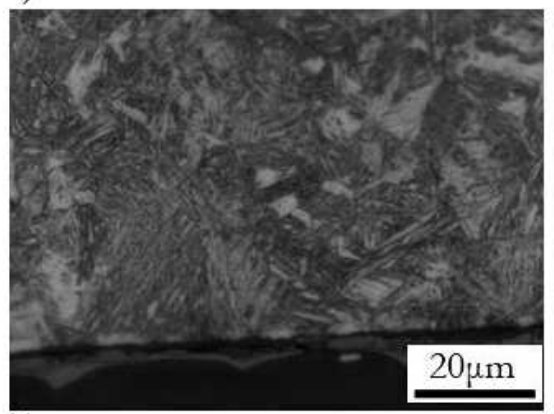

h)

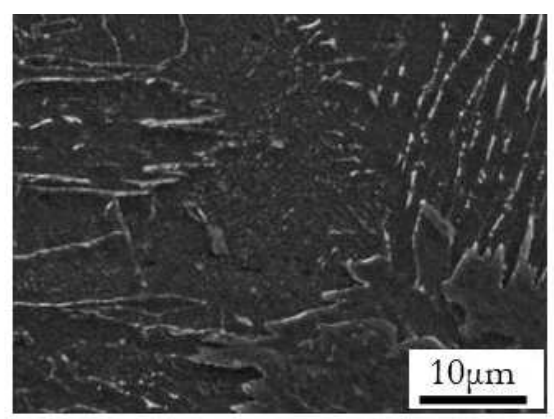

c)

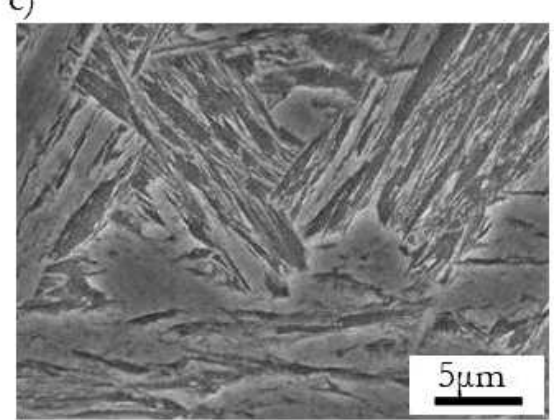

f)

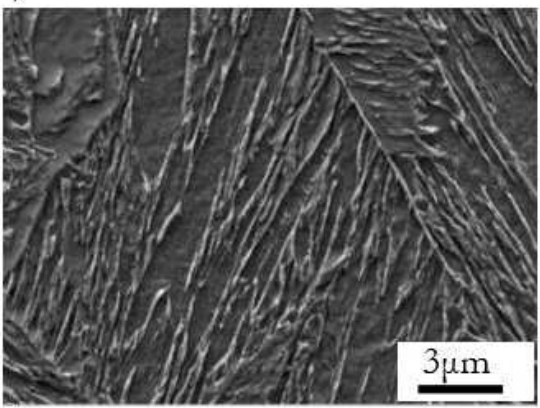

i)

Fig. 3 Longitudinal cross-sections of samples cut by acetylene a) - c), laser d) - f) and plasma g) - i). Affected layers at the surface in overview images a), d), g) light micrographs b), e), b) and SEM (c), f), i).

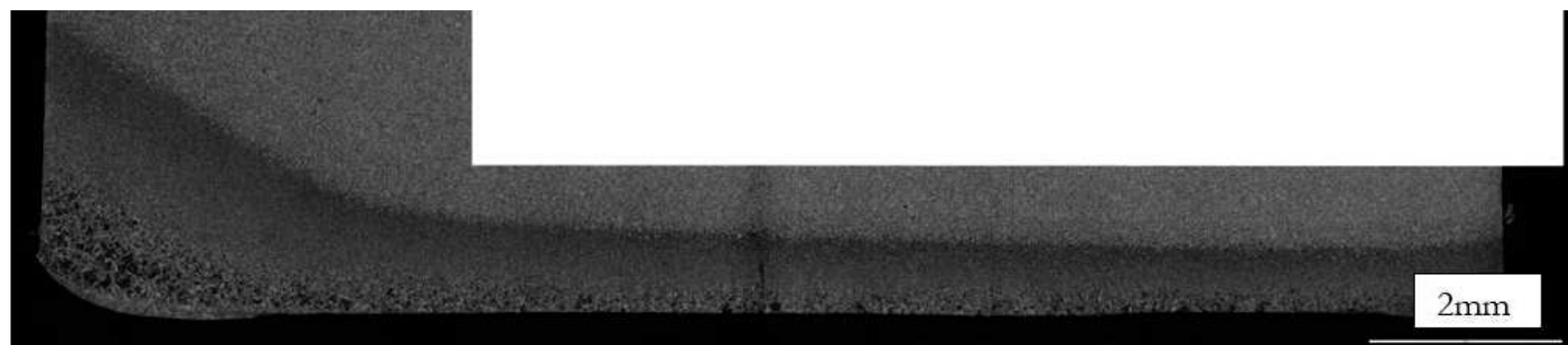

a) Acetylene

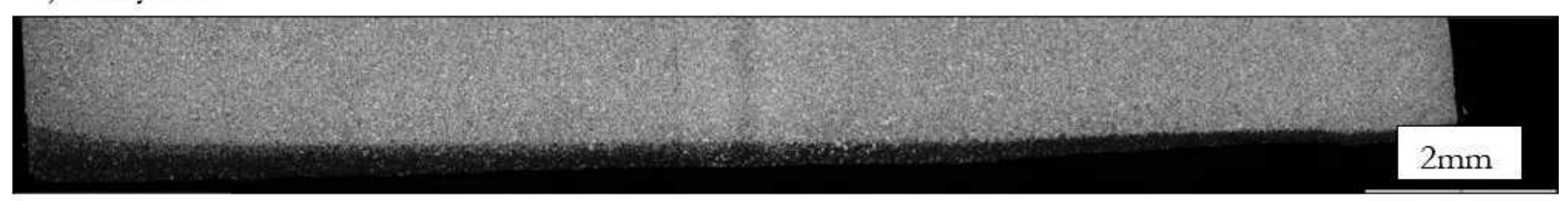

b) Laser

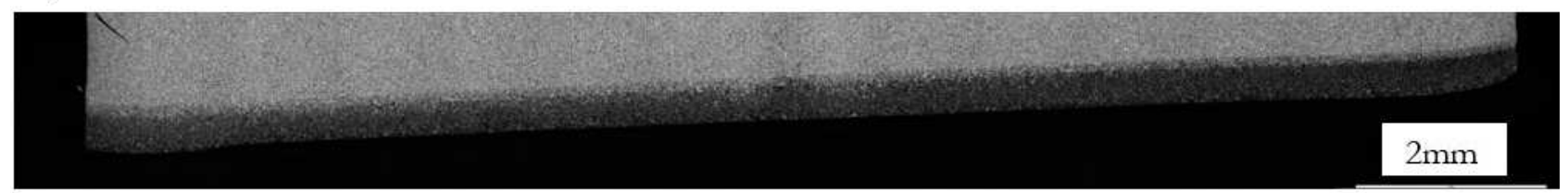

c) Plasma

Fig. 4 Stitched images of transverse cross-section, a) acetylene, b) laser, c) plasma 


\section{Stitched images of transverse cross-sections}

The uneven depth of influenced layers was visible on all stitched images of transverse cross-sections of cut plates (Fig. 4). The biggest difference in the depth was observed in the samples cut by acetylene (Fig. 4a). In this case, the depth of the surface layer at the more affected bottom side was nearly four times bigger than the depth of the layer at the opposite, upper, side of the steel plate. The same trend is apparent in the surface cut by laser (Fig. 4b), where the more affected side has around three times a deeper surface layer than the opposite one, even though it still does not make even the smallest depth of acetylene affected layer. Quite an even surface layer development was observed for plasma cut surface (Fig. 4c), where practically no depth differences can be observed between the upper and the lower side of the steel plate.

\subsection{Microhardness and nanohardness measurement}

Microhardness development was determined at longitudinal cross-sections, starting always from the cut surface. The imprints were carried out every $0.1 \mathrm{~mm}$ in the direction normal to the surface, using $100 \mathrm{~g}$ loading force.

Acetylene cutting resulted in the smallest change of surface hardness and was accompanied by a drop of hardness at the very surface. However, the total influenced layer in the material cut by acetylene reached the biggest depth under the surface, which was the reason why the measurement was, in this case, carried out up to $4 \mathrm{~mm}$ (Fig. 5). The hardness decreased gradually with increasing depth below the cut surface and the obtained maximal hardness of $260 \mathrm{HV} 0.1$ was achieved $0.25 \mathrm{~mm}$ below the surface. The relative softness of the affected surface layer corresponds to observed ferrite- bainite microstructure

Both laser and plasma cut surfaces showed more than twice higher surface hardness than the base material (Fig. 6). This high hardness resulted from quenched microstructures below the surfaces. The laser-cut surface reached the highest hardness of 400 HV0.1.

Nanoindentation was used as an additional method for hardness development evaluation. A loading force of $0.98 \mathrm{~N}$ (circa $0.1 \mathrm{~g}$ ) with the distance between imprints being 46 micrometres. Nanoindentation values are given in Pascals and they cannot be directly compared or converted into values comparable with standard Vickers hardness determined in previous tests. Due to the very low loading forces and small resulting imprints, the measurements near the surface of the sample should be more precise and reliable than conventional microhardnes. On the other hand, generally larger scatter of measured values can be expected for nanoindentation measurements, as they are extremely sensitive to local microstructure features. And even small microstructure heterogeneity of the plate can affect the measurement. It can be seen from the comparison of Fig. 6 and Fig. 7, that both graphs capture the same trend in surface hardness of individual samples. Laser and plasma cut samples had very similar, extremely increased micro and nano hardnesses just below the cut surface and the harnesses of both samples rapidly decrease in a similar depth below the surface.

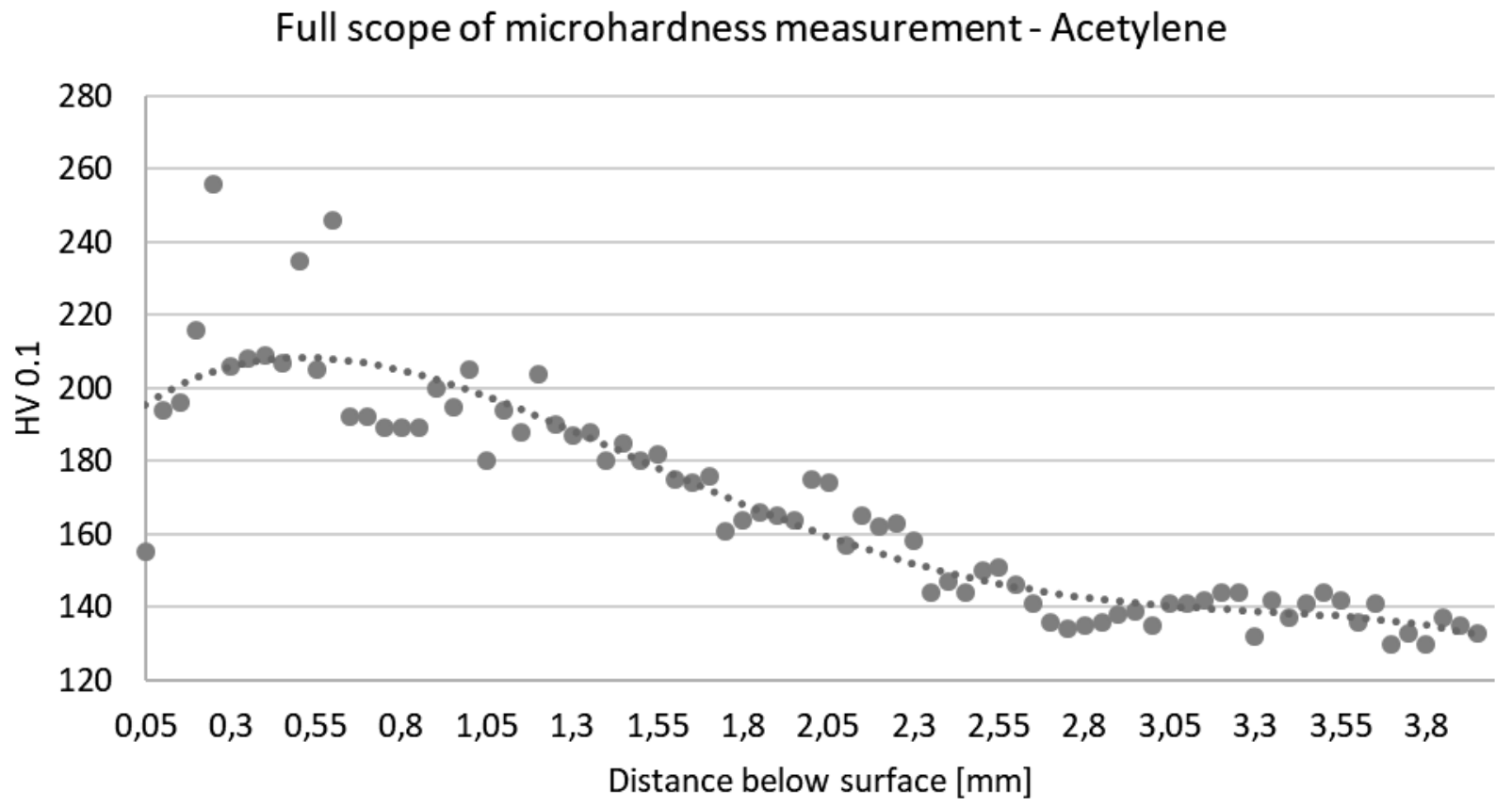

Fig. 5 Dashed black line marks the trend of hardness development, which was used to determine the depth of influenced surface to be around $2.85 \mathrm{~mm}$. 


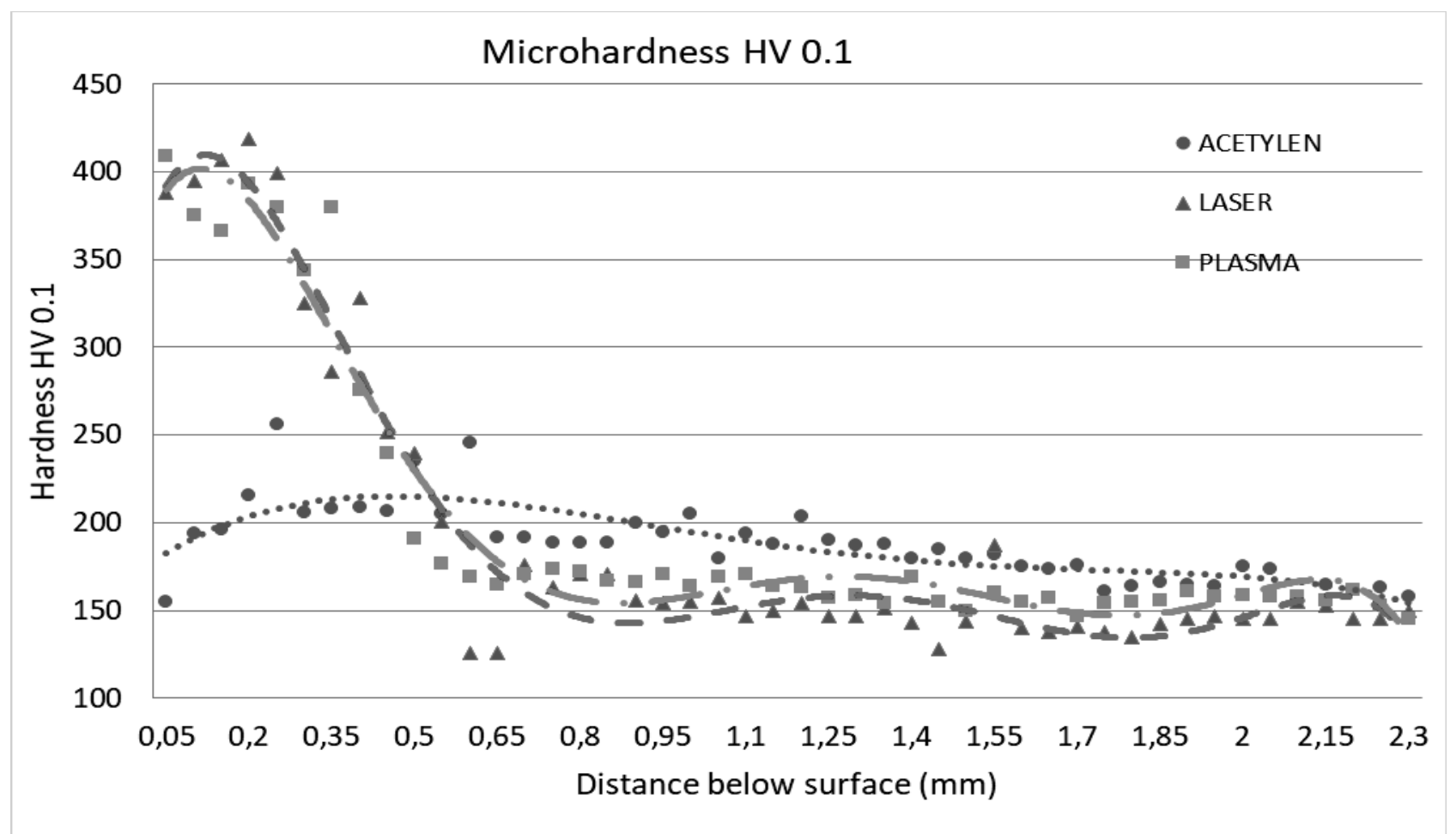

Fig. 6 Comparison of microhardness development

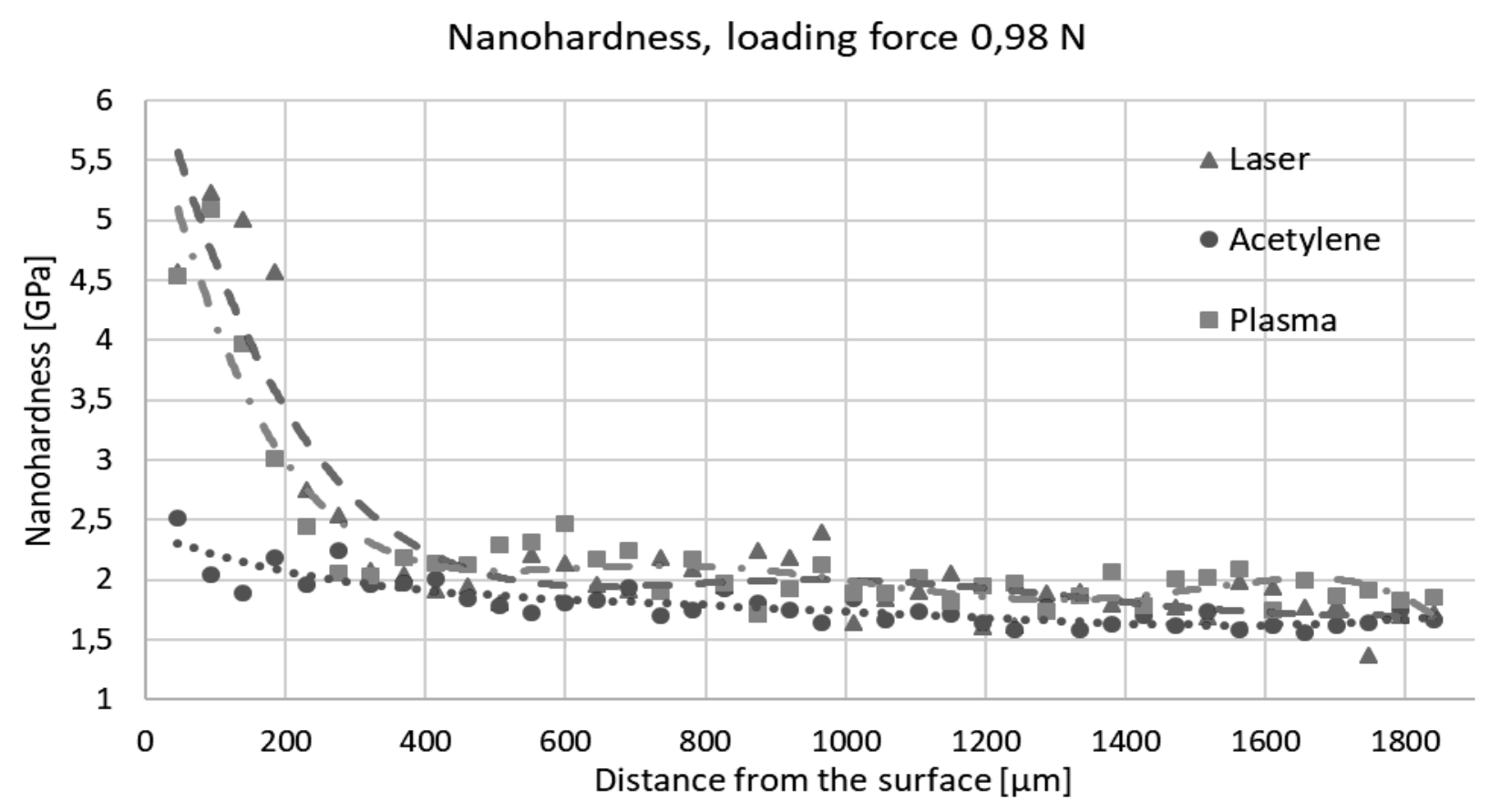

Fig. 7Nanohardness, loading force 0,98 N

\subsection{Determination of the depth of influenced layers}

The depth of influenced layers was evaluated by three methods. First of all, image analysis was applied to light micrographs taken by the lens with a magnification of $5 \mathrm{x}$. The values provided in table 1 are the average of 15 measurements from 3 different micrographs. This evaluation was based purely on the visual difference of microstructures of influenced layers.

Microhardness and nanohardness curves were also evaluated for comparison. Nano hardness was measured only at the distance of 1800 micrometres, which was not enough to evaluate the affected layer for the acetylene-cut sample. 
Tab. 1 Comparison of the depth of influenced layers determined by various methods

\begin{tabular}{|l|l|l|l|}
\hline Cutting technology & Depth of influenced layers $[\mu \mathrm{m}]$ & Nano-hardness \\
\hline & Image analysis & Micro-hardness & - \\
\hline Acetylene & 2980 & 2850 & 1000 \\
\hline Laser & 564 & 750 & 780 \\
\hline Plasma & 448 & 650 & \\
\hline
\end{tabular}

\section{Conclusions}

All three used technologies influence significantly microstructure and surface hardness of cut steel. Acetylene cutting resulted in the deepest affected zone consisting of several layers with gradually changing microstructures based on various ferritic-carbidic morphologies. However, from the point of view of surface properties, these layers possess similar hardness as the base material. Thinner layers with higher hardness and bainitic microstructure were created by plasma cutting. Laser cutting resulted also in thin affected surface layers with bainitic-martensitic microstructure and with the thickness being between plasma and acetylene.

\section{Acknowledgement}

The present contribution has been prepared within project LO1502 Development of the Regional Technological Institute' under the auspices of the National Sustainability Programme I of the Ministry of Education, Youth and Sports of the Czech Republic.

\section{References}

[1] PESSOA, D.F., HERWIG, P., WETZIG, A., ZIMMERMANN, M. (2017). Influence of surface condition due to laser beam cutting on the fatigue behaviour of metastable austenitic stainless steel AISI 304. In: Eng. Fract. Mech., 185 pp. $227-240$.

[2] THOMAS, D.J. (2016) Optimizing laser cutedge durability for steel structures in high stress application. In: J. Constr. Steel Res., 121, pp. $40-$ 49.

[3] ORISCHICH, M.A., MALIKOV, A.G., SHULYATYEV, V.B., GOLYSHEV, A.A. (2014). Experimental comparison of laser cutting of steel with fibre and CO2 lasers on the basis of minimal roughness. In: Phys. Procedia, 56 , pp. $875-884$.

[4] YILBAS, B.S. (2004). Laser cutting quality assessment and thermal efficiency analysis. In: $J$. Mater. Process. Technol., 155-156, pp. 2106 2115.

[5] DOBROCKY, D., POKORNÝ, Z., STUDENY, Z., DOSTAL, P. (2019). Change of Selected parameters of Steel Surface after
Plasma Nitriding. In: Manuf. Technol., 19(2), pp. $204-208$.

[6] CARISTAN, C.L. (2004). Laser cutting guide for manufacturing, Michigan, pp. 211 - 229. Society of manufacturing engineers, Michigan, USA.

[7] GOPPOLD, C., ZENGER, K., HERWIG, P., WETZIG, A., MAHRLE, A., BEYER, E. (2014). Experimental analysis for improvements of process efficiency and cut edge quality of fusion cutting with $1 \mathrm{~mm}$ laser radiation. In: Phys Procedia, 56, pp. 892 - 900.

[8] PIPINATO, A., PELLEGRINO, C., BURSI, O.S., MODENA, C. (2009). High-cycle fatigue behavior of riveted connections for railway metal bridges. In: J. Constr. Steel Res., 65/12, pp. $2167-2175$.

[9] STANCEKOVA, D., DRBUL, M., JANOTA, M., NAPRSTKOVA, N., KULLA, A., MRAZIK, J. (2016). Influence of manufacturing parameters on final quality of lapped parts. In: Manuf. Technol., 16(1), pp. 253 - 59.

[10] SPENA, P.R. (2017). CO2 laser cutting of hot stamping boron steel sheets. In: Metals, 7/11, pp. 456-473.

[11] KREAJCARZ, D. (2014). Comparison metal water jet cutting with laser and plasma cutting. In: Procedia Eng., 69, pp 838 - 843.

[12] SOLONITIS, K., VATOUSIANOS, S. (2012). Experimental investigation of the plasma arc cutting process. In: Procedia CIRP, Vol. 3, pp. $287-292$.

[13] NOVAK, M., NAPRSTKOVA, M. (2014). The influence of cutting conditions on surface roughness during steel X38CrMoV5 grinding. In: Key Eng. Mater., 581, pp. 247 - 254.

[14] NOVAK, M., NAPRSTKOVA, M. (2015). Grinding of the alloy INCONEL 718 and final roughness of the surface and material share. In: Manuf. Technol., 15(6), pp. 1015 - 1023.

[15] AKKURT A. (2015) The effect of cutting process on surface microstructure and hardness of pure and $\mathrm{Al} 6061$ aluminium alloy. In: Eng. Sci. Technol. Int. J., 18, pp.303 - 308. 